\title{
Serviço alternativo de Proteção Especial a Criança e ao Adolescente (SAPECA)
}

As Autoras

\section{Jacqueline I. Machado Brigagão}

Doutora em Psicologia pelo Instituto de Psicologia da Universidade de São Paulo. Professora da Universidade São Marcos e Pesquisadora do Programa Gestão Pública e Cidadania.

\section{Gabriela de Matos Rizzo}

Aluna do curso de Administração de Empresas da Escola de Administração de Empresas de São Paulo Fundação Getúlio Vargas. 


\section{Serviço alternativo de Proteção Especial a Criança e ao Adolescente (SAPECA)}

A violência doméstica atinge crianças e adolescentes no mundo todo e de todas as classes sociais. Como essa modalidade de violência é cometida, na maioria das vezes, no espaço privado do lar a sua identificação nem sempre é fácil. Souza, afirma:

A criança que sofre violência no âmbito de seu lar só passa a existir como vitimizada quando o fato for comunicado, fazendo com que o sistema de proteção seja acionado. Quer seja sob a denúncia ou a notificação, a transposição de comportamentos da esfera da intimidade à esfera pública, em geral, acontece quando a violência é recorrente e seu grau de severidade ultrapassa a margem de tolerância do público pelo excesso insuportável do privado.

O SAPECA - Serviço Alternativo de Proteção Especial à Criança e ao Adolescente, é um projeto que busca trabalhar com essa problemática, de forma inovadora e comprometida com os direitos do cidadão.O projeto vem sendo desenvolvido pela Secretária Municipal de Assistência Social, da Prefeitura Municipal de Campinas desde junho de 1997. O objetivo central é atender provisoriamente a criança vítima de violência doméstica em famílias acolhedoras possibilitando a efetivação de uma política de proteção a família natural, favorecendo o rompimento do ciclo de violência e não permitindo a institucionalização destas crianças. Atualmente o projeto atende crianças na faixa etária de 0 a 6 anos que são retiradas de suas famílias de origem por estarem sendo vítimas de alguma forma de violência.

\section{Histórico}

O SAPECA surgiu em julho de 1997 e foi fruto das angústias e indagações de uma equipe de profissionais, composta por psicólogas e assistentes sociais, vinculadas a Secretaria Municipal de Assistência Social de Campinas. Elas assistiam as crianças serem retiradas de suas famílias e serem enviadas ao Abrigo Municipal, onde muitas permaneciam longos períodos e sofriam todas as conseqüências da institucionalização como a ausência de vínculos afetivos e de modelos relacionais. Muitas dessas crianças eram enviadas diretamente para adoção sem que nenhum trabalho fosse realizado com a família de origem. Maria Helena, uma das idealizadoras do projeto, nos disse que, sentia-se muito mal com o fato do Estado retirar as crianças das famílias sem se preocupar com os direitos da família de criar os seus filhos e de não haver nenhum investimento no potencial destas famílias para romper com o ciclo de violência, se reorganizar e poder criar as suas crianças.

Como a equipe já estava sensibilizada com as questões da violência doméstica, entendiam que as famílias naturais também eram vítimas, já que os estudos sobre violência doméstica 
demonstram que este é um comportamento em grande parte aprendido e profundamente ancorado nas relações de gênero. Saffiotti (2003-332) discutinod essa questão afirma: "Embora admita-se a causação multifatorial da violência doméstica, frisa-se que a ordem patriarcal de gênero tem um peso extraordiamente grande". Então, esta equipe elaborou um modelo de atendimento onde as famílias naturais são atendidas para que possam romper com os modelos violentos de relação, ao mesmo tempo, que as crianças são colocadas em famílias substitutas evitando deste modo a institucionalização..

Esse projeto surgiu da experiência de trabalho com crianças vítimas de violência doméstica, de leituras, pesquisas e de visitas a SOBEM de São José do Campos que desde 1979 vinha realizando a colocação familiar de crianças vítimas de violência doméstica.

Na primeira fase, o trabalho focalizou a divulgação da proposta tanto na sociedade civil como dentro da rede municipal. Os membros do Conselho Municipal da Criança e do Adolescente participaram de reuniões com a equipe para a aprovação do projeto e a liberação de financiamento de parte dos recursos pelo Fundo Municipal da Criança e do Adolescente. Desde a sua implantação, o projeto contou com o apoio do Conselho Municipal dos Direitos da Criança e do Adolescente, do então Juiz da Vara da Infância e da Juventude e da Prefeitura de Campinas. Esses apoios tem sido fundamentais na continuidade do projeto e apesar das três mudanças partidárias no município o SAPECA permanece como sendo uma real alternativa a institucionalização para as crianças em risco pessoal e social.

Em 1999 a equipe do Programa sob a supervisão do LACRI - Laboratório de Estudo da Criança do Instituto de Psicologia da Universidade de São Paulo - realizou um processo de avaliação das ações e de consolidação do referencial teórico adotado pelo programa.

\section{A Equipe do Programa:}

O Programa conta atualmente com duas assistentes sociais, uma psicóloga, uma secretária, um motorista e uma coordenadora do projeto, todos eles funcionários da prefeitura municipal de Campinas. A equipe conta ainda com a colaboração voluntária de uma médica homeopata e uma arte-educadora. O "modus operandi “ do Programa procura articular a rede de proteção social na qual esta inserida esta família. Essa rede é entendida em sentido amplo e dela participam tanto outros programas governamentais, quanto agentes da sociedade civil. O atendimento de cada caso envolve, uma minuciosa análise da rede específica de cada família, e busca-se o diálogo e o envolvimento dos diversos atores sociais que possam auxiliar esta família neste processo. Essa rede é aberta e pode envolver quantos parceiros forem necessários. Na maioria das vezes envolve as instituições publicas que prestam serviços 
básicos (como as creches, escolas e postos de saúde), as instituições privadas (como por exemplo, uma clínica de recuperação para usuários de drogas que esta tratando gratuitamente de uma mãe que tem dois filhos no SAPECA), diversas ONGs, profissionais liberais, parentes e vizinhos das famílias atendidas, entre outros.

\section{As famílias acolhedoras:}

As famílias acolhedoras são famílias ou pessoas que se dispõe a acolher em seus lares, pelo tempo que for necessário, crianças vítimas de violência doméstica e que por medida de proteção foram retiradas de sua família natural. O compromisso da família acolhedora e de oferecer os cuidados básicos, bem como, amor e carinho, além possibilitar a essa criança uma convivência saudável e novos modelos de relacionamento afetivo e social. Atualmente o programa tem 22 famílias cadastradas, sendo que não é preciso ser casado, algumas mulheres separadas ou solteiras participam ativamente do Programa. O Processo para se tornar família acolhedora envolve, visitas, várias reuniões com a equipe do programa e um treinamento realizado durante oito semanas, cujo objetivo e capacitar as famílias candidatas para lidar com a problemática da violência doméstica e com os possíveis problemas a serem enfrentados durante o acolhimento. Neste período, a equipe do programa observa o potencial das famílias candidatas para se tornarem famílias acolhedoras e ao final do treinamento decidem junto com a família, se ela está preparada para se tornar famílias acolhedoras ou não. Isto significa dizer que nem todas as famílias treinadas são cadastradas. Somente ao final do treinamento as famílias são informadas que receberão uma ajuda de custo no valor de um salário mínimo para cada criança acolhida.

Tivemos a oportunidade de conversar com oito famílias que estão acolhendo crianças neste momento e todas elas demonstraram um investimento afetivo muito grande na relação com as crianças acolhidas e algumas parecem gastar mais do que a bolsa auxílio para manter as crianças em boas escolas.

A bolsa é oferecida no sentido de auxiliar as famílias, mas também de garantir que o Estado está se responsabilizando financeiramente por essas crianças que foram retiradas de suas famílias.

De um modo geral podemos dizer que as famílias acolhedoras são de classe média e média/baixa e as famílias naturais são pobres, mas de acordo com os depoimentos que ouvimos esse fator parece não estar interferindo na volta para as famílias naturais. 
Pareceu-nos um ponto positivo o fato de as famílias acolhedoras não precisarem do dinheiro da bolsa para sobreviver. Nos EUA há uma discussão acerca do Programa de colocação familiar, já que em muitos casos, o acolhimento se tornou um meio de vida para as famílias mais carentes, o que interfere muito na qualidade do acolhimento.

Os membros do Programa, afirmam que eles tem dificuldades de mobilizar mais famílias devido a idéia de o acolhimento ser provisório, as pessoas tem dificuldades de lidar com a idéia do cuidado provisório, se fosse adoção talvez fosse mais fácil.

\section{A rotina de trabalho}

Atualmente o trabalho desenvolvido pelo SAPECA segue a seguinte rotina, as crianças são encaminhadas ao Programa pelo Conselho Tutelar ou pela Vara da Infância e da Juventude ou ainda pelo Abrigo Municipal o SAPECA encaminha essas crianças a uma das famílias acolhedoras cadastradas e com disponibilidade para receber a criança. No caso de irmãos, o abrigamento deve ser feito em uma mesma família. Esse processo é acompanhado de perto pela Assistente social responsável pelo caso que realiza visitas semanais a família acolhedora, sendo que neste primeiro momento do acolhimento o contato telefônico é diário e as visitas também são mais freqüentes. Essa criança é atendida semanalmente pela psicóloga da equipe e participa dos grupos de arte-terapia realizados uma vez por mês em grupo com as outras crianças que também estão vivendo em famílias acolhedoras.

As famílias acolhedoras participam de duas reuniões mensais na sede do Programa. A reunião geral é realizada a noite e objetiva discutir as questões relativas ao Programa e a efetivação da rede de proteção à criança e ao adolescente. O Programa busca promover o protagonismo dos usuários e espera que todos participem ativamente das decisões e da elaboração das metas do Programa. A outra reunião é matutina, este é o momento que as famílias tem para compartilhar seus sentimentos pensamentos e dúvidas acerca do acolhimento.

Desde o momento da chegada da criança no SAPECA, inicia-se um processo de avaliação psicossocial com a família natural da criança, o qual irá buscar identificar as potencialidades desta família e as possibilidades de ajudá-la. A família natural é informada que a criança está no SAPECA e logo no primeiro encontro eles são informados de que a criança está bem e está com um família acolhedora. Os endereços das famílias acolhedoras não são fornecidos as famílias naturais, é a equipe do Programa que irá intermediar as relações e os encontros entre a criança e sua família de origem, ou seja, o ponto de referência é a sede do SAPECA. Esses encontros com a família natural objetivam manter os vínculos da criança com sua família e 
não deixar que haja um corte brusco na história pessoal da criança, ou seja, as crianças sabem o tempo todo que estão em um acolhimento provisório e que a sua família esta sendo preparada para recebê-la de volta. Como já dissemos anteriormente, a família é entendida em um sentido extenso e inclui pai, mãe, irmãos, tios, avós e mesmo outras pessoas significativas da história de vida dessa criança.

Vale lembrar, que mesmo crianças vítimas de algum tipo de violência sofrem ao serem separados de suas famílias e da rotina diária a que estão acostumadas, especialmente nesta faixa etária de 0 a 6 anos. Assim, poder continuar recebendo visitas de alguns membros de sua família além de minimizar as fantasias e medos gerados pelo acolhimento possibilita a criança a sensação de continuidade e o não rompimento com a própria história.

Durante todo o período de acolhimento é realizado um trabalho com a família de origem que também realiza encontros semanais com as assistentes sociais, seja em visita domiciliar, seja na sede do Programa. O tempo de acolhimento não é predeterminado e varia de acordo com cada caso. De um modo geral, nos casos que observamos, podemos dizer que está variando entre seis meses a três anos. Após a volta da criança para a família natural eles continuam sendo acompanhados pelo Programa por um período de cinco anos. É interessante observar que quando há o retorno, a família toda é acompanhada e o trabalho inclui os irmãos e as outras crianças que vivem nesta família.

Para que este processo fique mais claro, vamos contar uma das historias de uma criança atendida pelo SAPECA que tivemos a oportunidade de conhecer.

Fomos visitar a família de Rafael $^{1}$, eles vivem na periferia de Campinas e faz apenas 20 dias que ele voltou a viver com o seu pai, o Sr. João. Todos na casa pareciam muito felizes com a nova configuração familiar. O pai de Rafael vive há dois anos com uma jovem chamada Maria que tem uma filha de 5 anos e que o chama de pai. A mãe natural de Rafael sempre teve dificuldades de cuidar dele, então quando ele tinha 11 meses ela concordou que João passasse a cuidar do menino. Mas, quando a criança tinha 1 ano e 8 meses, ela foi à creche e levou Rafael com ela, João foi atrás mas não conseguiu convencer a mãe a deixá-lo a levar o menino de volta. Ele mudou de casa, de trabalho e não teve mais noticias do filho. Mas, a mãe continuou sendo negligente no cuidado com Rafael e ele estava em situação de risco pessoal e social e foi retirado da casa da mãe pelo Conselho Tutelar. Após a avaliação psicossocial da situação, a equipe do SAPECA iniciou um processo de busca do pai. Ele nos conta 
emocionado sobre o dia que recebeu o telefonema da assistente social: "eu pensei, achei meu filho”. A partir daí, o SAPECA começou a realizar encontros entre João e Rafael reaproximando-os e auxiliando na articulação da rede social de proteção que possibilitaria a reestruturação da família, já que nem João e nem Maria estavam trabalhando, o SAPECA ajudou-os neste processo. Rafael ficou em acolhimento durante 1 ano e acaba de voltar para o convívio com o pai. João nos conta do encontro que teve com a família acolhedora: “É engraçado porque é meu filho e eles conheciam ele mais do que eu, e foi tão ótimo para mim e para a Maria, até para ele mesmo e tudo que ela falou, a Joana faz assim com ele, que ele é assim, tudo certinho, foi uma ajuda que não é outro pai que tem uma sorte que nem eu não.”

É interessante pontuar nesta historia que o programa está preocupado com as questões de gênero e que reconhece e respeita o direito a paternidade rompendo com a idéia culturalmente defendida que os filhos devem viver com as mães. Nós conhecemos também o pai do José, que é solteiro e está cuidando do filho, ele conta com ajuda das irmãs e das vizinhas no dia a dia.

Quanto ao modo como as crianças vivenciam esta situação foi possível perceber através dos depoimentos dos membros do programa, das famílias naturais, das famílias acolhedoras e das crianças em acolhimento que elas se adaptam as famílias acolhedoras e fazem vínculos, mas que conseguem fazer a transição para as famílias naturais com relativa tranqüilidade e após algum tempo estão completamente adaptadas.

Infelizmente, quando visitamos duas das famílias naturais que tiveram seus filhos acolhidos por um período não foi possível conversar com as crianças porque elas estavam na escola. Mas, os relatos sobre a adaptação deles são muito interessantes, por exemplo, o José quando chegou ao programa tinha muitas dificuldades de se expressar, os desenho dele eram considerados muito "primitivos" para a idade cronológica. No "prontuário” dele há um dos primeiros desenhos que fez ao chegar ao Programa neste desenho ele se representava como uma gota de água. Quando ele passa a viver com o pai natural, ele faz um desenho na escola que retrata ele e o pai soltando pipa. Esse desenho foi premiado e a escola fez uma camiseta para todas as crianças com esse desenho estampado. O pai dele nos contou, que soltar pipa era a brincadeira favorita dele quando criança, e que ao se re-aproximar do filho volta a brincar de soltar pipas com o filho.

O Rafael, que apresentamos acima, também parece estar se adaptando com facilidade. Ele voltou a viver com o pai, mas continua na mesma escola que as crianças da família acolhedora, ele disse na escola para os amigos (irmãos acolhedores) que gosta muito deles e dos pais deles, mas que quer ficar morando com o pai. E o pai dele nos contou, que ele está 
sempre perguntando sobre como ele era quando pequeno e que pede para ir aos lugares que ele freqüentava quando bebe.

Parece que esse retorno para a família natural tem sido tranqüila, apesar das diferenças entre as classes sociais, nas famílias acolhedoras as condições sócio-econômicas são melhores que nas famílias naturais.

A psicóloga atribui o sucesso dessas experiências ao fato das crianças não terem perdido o contato com a família natural durante todo o período do acolhimento, receberam visitas, realizaram passeios juntos e sabiam todo o tempo que retornariam para as suas famílias. Esse sentimento de pertencimento a sua família é trabalhado em todos os atendimentos.

\section{As limitações:}

Pareceu-nos que o programa atendeu um número pequeno de crianças ao longo do tempo, mas não podemos esquecer que todo o trabalho é realizado apenas por uma equipe e os serviços oferecidos são de altíssima qualidade é feito o acompanhamento individualizado das crianças, das famílias naturais e das famílias acolhedoras. Vejamos o número de crianças e famílias atendidas pelo Programa até o momento:

11 crianças em acolhimento - 7 meninos e 4 meninas.

9 famílias acolhendo, sendo estas compostas por 5 homens e sete mulheres.

21 crianças em acompanhamento após o retorno a família natural, sendo 7 meninas e 14 meninos - esse número inclui as outras crianças que vivem com a família.

28 famílias naturais e extensas - 28 mulheres e 14 homens.

22 famílias acolhedoras participantes - 23 mulheres e 12 homens.

6 famílias em treinamento - 6 mulheres e 4 homens

6 crianças que foram encaminhadas para adoção.

3 crianças que passaram pelo programa sem acompanhamento atual - 2 meninos e 1 menina - isto ocorreu devido a mudança de município ou estado ou ainda a colocação em abrigo.

Vale ressaltar que estes números podem já ter sido alterados, já que este é um processo dinâmico e ao mesmo tempo que entram novas crianças outras retornam para as famílias naturais. 
Um outro aspecto que parece impedir o crescimento do Programa e a expansão das ações é o orçamento. O Programa sobrevive exclusivamente com recursos públicos, sendo que, o gasto total anual incluindo os salários, os gastos com manutenção e as bolsas-auxílio oferecidas as famílias substitutas perfaz o total de R\$214.599,85. A equipe do Programa, tem trabalhado no sentido de conseguir parceiros na sociedade civil que contribuem prestando serviços, como por exemplo, o ortodontista que atende gratuitamente uma das meninas do Programa, mas ainda não conseguiu parceiros que queiram investir financeiramente no projeto. A coordenadora disse ter procurado empresas, mas que por enquanto, ainda não conseguiu nenhum apoio financeiro, muitas vezes as empresas não querem associar-se a programas da prefeitura para não configurar apoio político partidário.

Uma outra limitação que identificamos foi a restrição do atendimento a crianças somente na faixa etária de 0 a 6 anos, o que contradiz os objetivos do Programa e mesmo o nome que prevê o atendimento de adolescentes. Este limite será superado em breve já que eles estão tentando implantar um projeto de reestruturação organizacional, que já foi aprovado, para que parte das crianças e adolescentes que são atendidas no abrigo municipal sejam transferidas para famílias acolhedoras através do SAPECA. A idéia inicial é transferir 30 das 65 crianças e adolescentes que estão no Abrigo Municipal e acompanhá-las dentro do programa.

Quando perguntamos aos membros da equipe acerca das principais dificuldades ou limitações que eles enfrentam eles responderam que a duas principais dificuldades são: encontrar famílias acolhedoras e as questões relativas à guarda judicial da criança.

Quanto a encontrar famílias acolhedoras eles tem feito esforços diversos com a pouca verba com que contam para divulgar o programa e sensibilizar as pessoas para que participem e se candidatem a ser famílias acolhedoras. No ano de 2001 conseguiram que uma agência de publicidade elaborasse gratuitamente uma campanha de divulgação, o que aumentou em muito a procura de informações. O programa já utilizou diferentes estratégias como a colocação de anúncio na conta de água, cartazes em ônibus, divulgação corpo a corpo na feira de artesanato da cidade. De acordo com os dados apresentados pelo programa a diferença entre o numero de pessoas que procuraram informações e foram concretamente treinadas e se tornaram famílias acolhedoras é muito grande. No total 492 pessoas, desde o início do programa, procuraram informações sendo que apenas 29 se tornaram famílias acolhedoras. Deste modo, a equipe do programa e também as famílias acolhedoras com quem conversamos, apontam como dificuldade não apenas a divulgação, mas também a cultura individualista em que vivemos onde a solidariedade não é valorizada. Uma das mulheres que esta fazendo o acolhimento sozinha disse no grupo de pais que participamos: "Ler o ECA no treinamento foi muito bom porque eu 
entendi que as cuidar das crianças é responsabilidade de toda sociedade”. Um outro membro do grupo de famílias acolhedoras, afirmou: "estou aprendendo com eles o amor sem posse”.

Uma outra dificuldade tem sido a negociação com o Poder Judiciário, já que nem todos os juizes que passaram pela Vara da Infância e Juventude de Campinas compreendem a proposta. O principal obstáculo tem sido relativo a mudança de guarda da criança. O Programa não trabalha com a mudança de guarda da família de origem, já que a idéia é potencializar a família natural, para que esta possa exercer o cuidado e a proteção a seus membros como determina os artigos 226 e 227 da Constituição Federal. Atualmente a equipe do Programa esta discutindo a idéia de propor a guarda compartilhada, mas estas são idéias que precisam ser amadurecidas e fundamentadas antes de serem apresentadas ao poder judiciário.

\section{A replicabilidade}

O Projeto pode facilmente ser replicado em outras cidades e seria um modo de viabilizar ações que cumpram com as determinações do ECA- Estatuto da criança e do Adolescente. Apesar do ECA apresentar a família como um direito de toda criança e como referência básica no processo de socialização e preconizar o atendimento de crianças vitimas de violência doméstica em regime colocação familiar, especificamente em seu artigo - 90: “orientação e apoio sócio-familiar e apoio sócio-educativo em meio aberto” este processo não vem acontecendo. A maioria das crianças vítimas de violência doméstica no Brasil são encaminhadas para abrigos. Neste sentido, apesar desse projeto estar cumprindo a lei, ele inova em relação à maioria das práticas correntes neste campo. O Projeto tem recebido a visita de muitas ONGs e prefeituras interessadas em conhecer suas práticas. Recentemente receberam a visita de uma equipe da prefeitura municipal de São Paulo que pretende implantar um projeto similar. A comunidade Filhos da Providencia da Paróquia Imaculada Conceição de Diadema - SP, iniciou um projeto de acolhimento em famílias em 1999 e afirmam em sua web page terem se baseado na experiência do SAPECA para elaborar o projeto. Este parece ser um indicador do potencial de replicabilidade do projeto. Em nossas pesquisas encontramos poucas iniciativas como esta, identificamos um projeto similar no Rio de Janeiro desenvolvido pela ONG Terra dos Homens em parceria com a Secretaria Municipal do Desenvolvimento Social e a Pastoral do Menor.Identificamos também um projeto que esta se iniciando em Fortaleza.

\section{Os aspectos inovadores:}

O reconhecimento da complexidade do fenômeno da violência doméstica, permite que as ações sejam amplas e não se restrinjam a retirada da criança da família de origem mas que, 
toda a família seja objeto de atenção e de cuidados por parte do programa. Janete Valente, atual coordenadora do SAPECA expressa a visão do programa acerca da problemática da família: "Entendemos que a retirada de uma criança de sua família representa a ponta de um iceberg; quando procuramos conhecer a problemática que envolve o caso, descobrimos uma família precisando ser cuidada."

O atendimento em rede, a forma como o programa desenvolve suas ações é muito interessante e eficaz. Ao articular os diversos atores da rede social da família promove não só processos de inclusão, mas também de funcionamento coletivo. Giongo C.D. argumenta que: "Uma das possibilidades é a de reconhecer nas Redes Sociais fontes de recursos para alem da resolução do problema que leva a família a procurar ajuda buscando a satisfação das necessidades afetivas, informativas e materiais, bem como a potencialização dos recursos de todos os envolvidos no processo.”

O acolhimento em famílias, possibilita a criança a formação de vínculos, além de um cuidado individualizado, fundamental para seu desenvolvimento, o que não seria possível em instituições destinadas a abrigar crianças. As conseqüências da institucionalização de crianças são amplamente conhecidas e podemos dizer que do ponto de vista psicossocial, as crianças institucionalizadas estão muito vulneráveis.

A influência nas políticas públicas municipais é um indicador do reconhecimento público da efetividade do Programa e de seu caráter inovador em relação as práticas vigentes. A resolução no.27/03 de 16 de julho de 2003 do Conselho Municipal dos Direitos da Criança e do Adolescente, ao criar um política municipal baseada no programa é uma demonstração clara do impacto deste programa, bem como do potencial de replicabilidade. A resolução determina que “O Município implementará programas de Famílias Acolhedoras para crianças de 0 a 6 anos, para que dentro de um período máximo de 02 anos, não ocorram mais abrigamentos nessa faixa etária.”

A visita ao projeto, possibilitou-nos uma aproximação da complexidade da problemática e nos sensibilizou para a importância de criar políticas públicas que viabilizem ações que garantam o cumprimento do Estatuto da Criança e do Adolescente. Podemos apontar como pontos fortes do projeto: a qualidade dos serviços prestados, o acolhimento em famílias o reconhecimento dos direitos das famílias naturais, o enfrentamento da problemática da violência doméstica. A equipe do Programa é muito sensível e trata com muito carinho as crianças, as famílias acolhedoras e as famílias naturais. É possível observar um encadeamento dos princípios teóricos que orientam a proposta com as práticas desenvolvidas pela equipe e apesar da grande demanda a equipe não abre mão da qualidade do trabalho. O discurso das famílias acolhedoras 
e o envolvimento desses parecem ser indicadores da eficácia deste trabalho. Como ponto fraco, podemos apontar o fato de o Programa não ter conseguido viabilizar o atendimento de crianças acima dos 6 anos,como previa o projeto original. Um outro aspecto que discutimos com a equipe foi o prolongamento do acolhimento, algumas vezes por tempo indeterminado.

Vale lembrar, que a equipe do Programa é muito pequena e que para conseguir realizar um bom trabalho todos trabalham muitas horas extras e como essas horas não são remuneradas, criaram um banco de horas onde são registradas essas horas excedentes, mas a equipe ainda não tem conseguido compensar essas horas. Com o projeto de atendimento as crianças do abrigo municipal a equipe deverá crescer, mas o trabalho também irá aumentar. Apesar de todas as dificuldades que o projeto enfrenta podemos dizer que o SAPECA tem realizado ações efetivas no sentido de garantir o direito de crianças vítimas de violência doméstica a viver em família.

\section{Bibliografia}

Giongo C.D. - A perspectiva de rede social no trabalho com famílias - Trabalho apresentado no 10 Congresso Brasileiro de Assistência Social

Souza M.P. - A publicização da violência privada e a tutela da intimidade. Trabalho apresentado no 10 Congresso Brasileiro de Assistência Social

Saffioti H.I.B.- Violência contra a mulher e violência doméstica. In:Gênero e Democracia e Sociedade Brasileira - Bruschini C. e Unbehaum S. Editora 34 e Fundação Carlos Chagas 2002 .São Paulo. 


\section{Anexo I}

\section{Técnicos entrevistados:}

Padre Erly - Presidente do Conselho da Criança de Campinas

Maria Helena - Assistente social uma das idealizadoras do projeto. Atualmente trabalha na Secretária de Assistência social coordenando projetos de combate a violência doméstica.

Sandra - Psicóloga e membro do conselho tutelar da cidade de Campinas

Ivanir - Coordenadora dos Programas de assistência a família da cidade de Campinas.

Lise Roy - Diretora da assistência social da secretária de Assistência Social.

Rita - Secretária Municipal de Assistência Social.

Janete - Coordenadora do SAPECA.

Adriana e Fátima - Assistentes sociais do SAPECA

Daniela - Psicóloga do SAPECA

Sueli - Arte-educadora do SAPECA

Cristiane - Secretária

Eduardo - motorista

\section{Famílias naturais:}

Família natural de uma das crianças

Pai natural que voltou a viver com seu filho

\section{Famílias acolhedoras:}

Maria

Fabio

Ranieri

Ermelildo e Cida

Filomena

Maria do Carmo

Cléa

Regina

\section{Documentos consultados:}

Resolução No.06/01 de 22.10.2001 - CMDCA de Campinas

Resolução No.27/03 de 16 de julho de 2003 - CMDCA de Campinas

Projeto: Famílias Acolhedoras por grupos de irmãos albergados

Relatório de Gestão do Programa - ano 2002

Artigo: Construindo o Atendimento em Rede a uma Família - Janete Valente 